\title{
The Removal Force of Some Custom Impression Tray Materials
}

Ibtehal H Al-Zubaidy BDS, MSc (Assist Lect)
Department of Prosthetic Dentistry

College of Dentistry, University of Mosul

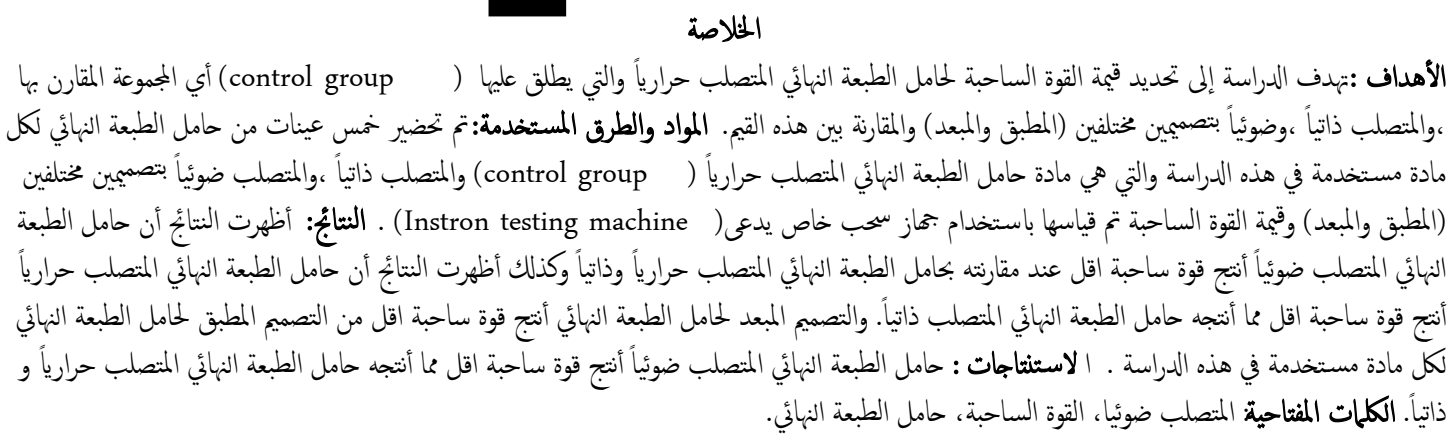

\begin{abstract}
Aims: The study aims to record the value of the removal force of heat cure (control group), cold cure and visible light cure with two design (close fit and spaced custom tray) and to compare between these values. Materials and Methods: Five custom trays was constructed for each materials used in this study which is heat cure(control group), cold cure and visible light cure resin with two design close fit and spaced custom tray and the value of the removal force was calculated by using instron testing machine. Results: The visible light cure custom tray produced less value of removal force when compared with the cold cure and heat cure custom trays and the heat cure custom tray produced a less value of removal force when compared with the cold cure custom trays. The spaced design produced less value in the removal force than the close fit design for each material used in this study. Conclusions: The visible light spaced custom trays produced less value of removal force than the cold and heat cure custom trays.
\end{abstract}

Key word: Visible light cure, Removal force, Custom tray, Bone resorption.

Al-Zubaidy IH. The Removal Force of Some Custom Impression Tray Materials. Al-Rafidain Dent J. $2010 ; 10(1): 25-29$.

Received: $2 / 4 / 2008$

Sent to Referees: $2 / 4 / 2008$

Accepted for Publication: $3 / 6 / 2008$

\section{INTRODUCTION}

The force required to remove a completed full - arch impression from the oral cavity is dependent on many factors, such as tray material and method by which the completed impression is removed. ${ }^{(1)}$

Auto polymerizing acrylic resin traditionally have been used for the fabrication of trays, however, concerns regarding the exposure of dental personal to the acrylic resin monomers have prompted a search for alternative tray material that are safe ,economical and easy to use. Visible light polymerizing resin were introduced, and manufacturers of these materials have suggested that they may be used with ease and success for making custom trays, and it is differ significantly from auto poly- merizing resin in both manipulation and mechanical properties. ${ }^{(2,3)}$

The force necessary to remove a completed impression from the oral cavity and the resulting internal stresses that an impression tray must resist without permanent deformation or fracture during removal have not been reported. ${ }^{(4,5)}$

The purpose of this investigation to record the value of the removal force of heat cure(control group), cold cure and visible light cure custom tray by single point of anterior force application, and to compare between these values of the removal force that affect on the stress distribution on the residual ridge and to compare between the close fit and the spaced design of the custom tray for the three materials used in this 
study for the construction of the custom trays in the values of the removal force.

\section{MATERIALS AND METHODS}

The master model, which is completely edentulous mandibular metal arch form (Co - Lumbia Dentform Corp, Long Island City, N.Y., U.S.A) was used for the construction of the custom tray on it. Heat cure as a control group (Quayle Dental - England), cold cure (DMPLtd E.U.) and visible light cure acrylic resin(Megatray, Mega-

Denta - Germany) was used for the construction of the custom trays with two design: close fit and spaced custom tray for each material used in this study ${ }^{(6)}$,five samples was made for each material and design .

Tray former $(16.5 \times 10 \times 2.5) \mathrm{cm}$ in dimension was made from dental stone and a piece of imprelon of $(2 \mathrm{~mm})$ thickness was trimmed according to the form and dimension of upper shellac base plate and placed in the centre of the frame, then a glass slab was placed above it to determine the dimension of tray former, after setting of stone (1 hour) the frame and the glass slab were removed. This tray former was used to determine the thickness and form of acrylic resin tray for all samples.

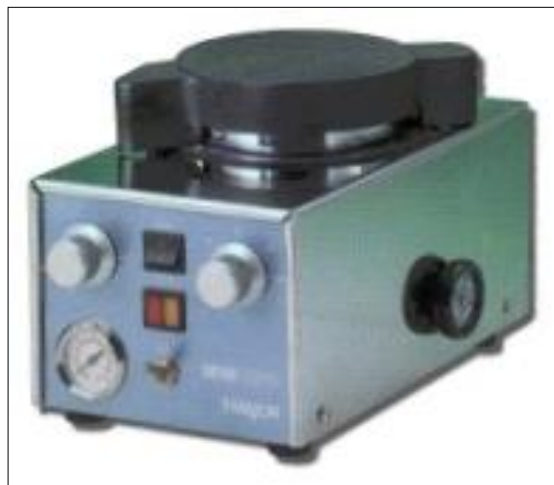

A

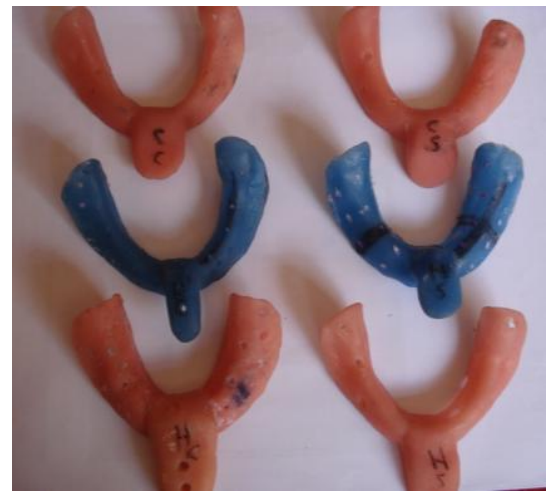

B

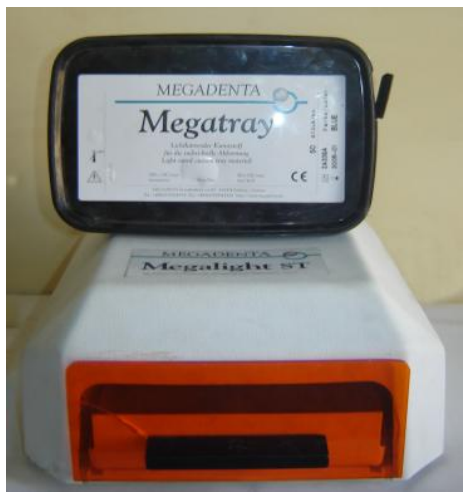

C

Figure(1): Devices and Materials Used in this Study:

A: Thermopress device; B: Custom Tray Materials; C: Visible light curing unit

All the custom trays were placed in distilled water for 24 hour before they were tested. Perforation was done on the centre of the handle for all trays by using bur.

The master model was moistened with natural saliva to simulate the patient's mouth, and then the supersil addition sili- cone impression material was mixed according to the manufacturer's instruction then the tray with the impression material was placed on the master model by applying the force of operator's hand (female) on the premolar region.

The force applied on the premolar region during taking the impression was 
measured by using digital indication hand dynamometer device, Figure(2), after the impression materials had set at room temperature $\left(23 \mp 2{ }^{\circ} \mathrm{C}\right)$, the thickness of impression material was detected by using endodontic reamer with stopper, which penetrates the impression material until it touches the tray (mean of accuracy $\mp 1.5 \mathrm{~mm}$ ) . The distance was measured by using the digital vernier it accuracy was $(0.01 \mathrm{~mm})$.

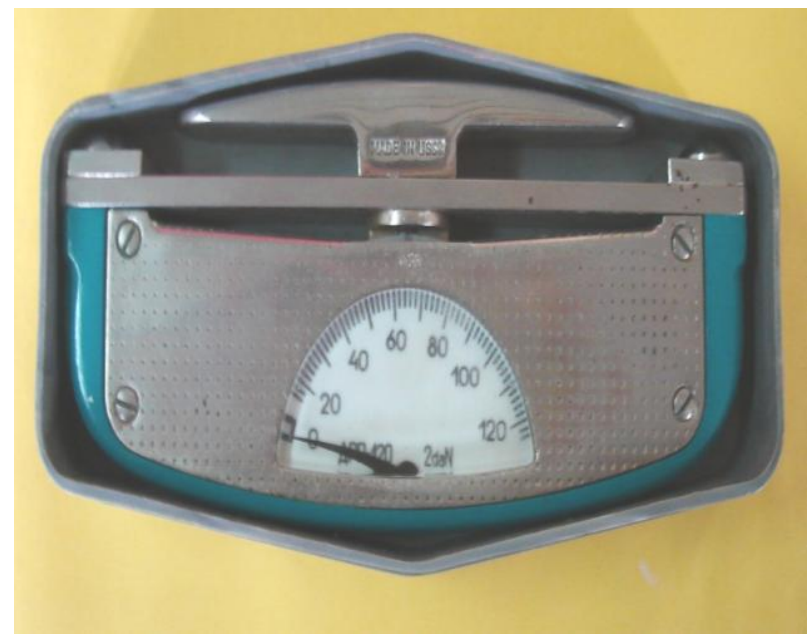

Figure (2): Digital Indication Hand dynamometer device

The master model with the custom tray and impression material on it were placed on the table of instron testing machine then a single point of anterior force removal was applied on the perforation that made on the centre of the handle for each custom tray that made in this study .

The instron testing machine consist of upper and lower part, the lower part consist of two section which can be open for distance not more than $(5 \mathrm{~cm})$ so that the master model was modified by using a piece of metal $(5 \mathrm{~cm})$ in length and $(1 \mathrm{~cm})$ in width which was fixed on the base of the master model, and put between the two section, and locked by using the screw of the lower part, after taking the impression a stainless steal wire gauge $(0.8 \mathrm{~mm})$ extended from the perforation that made on the centre of the handle of each special tray to the upper part of the instron testing machine that also consist of two section , and the wire was locked between these two section by using the screw of the upper part.

A straight upright tensile force was applied on the samples by start the work of the instron testing machine, Figure(3).

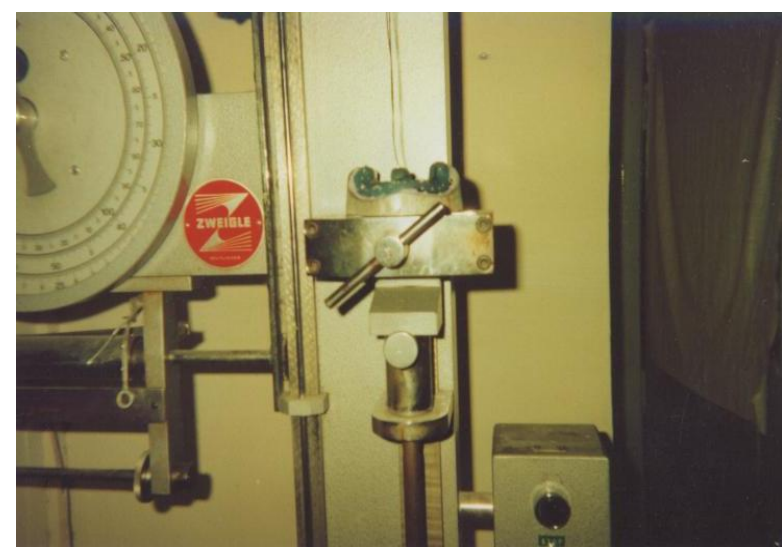

Figure(3): Custom Tray on the Instron Testing Machine

After the data were collected, appropriate statistical analyses which include 
mean difference, standard deviation, ANOVA, and Duncan analysis multiple range test were completed.

\section{RESULTS AND DISCUSSION}

In closed fit and spaced technique, five custom trays were constructed for each material used in this study (heat cure as a control group, cold cure and visible light cure resin material). The mean differences of tensile strength and standard deviation of all these types of the trays were shown in Table(1).

The results showed that the visible light custom trays produced less value in the removal force than the other types of custom trays.

One way analysis of variance (ANOVA) of all custom trays was shown in table(2) at $(\mathrm{P} \leq 0.05)$, the Duncan's multiple range test of all custom trays in relation to the control group was showed in Table (3).

Table (1): Mean Difference and Standard Deviation of the Close Fit and Spaced

Heat Cure (control group), Cold Cure and Visible Light Cure Custom Trays.

\begin{tabular}{cccc}
\hline Group & No. & Mean $(\mathbf{K g})$ & Standard deviation \\
\hline HC & 10 & 1.3 & 0.0816 \\
HS & 10 & 1.2 & 0.0738 \\
CC & 10 & 1.5 & 0.0667 \\
CS & 10 & 1.4 & 0.0816 \\
VC & 10 & 1.1 & 0.0943 \\
VS & 10 & 1.03 & 0.0483 \\
\hline
\end{tabular}

HC: heat cure close fit custom trays; HS: heat cure spaced custom trays CC: cold cure close ; fit custom tray; CS: cold cure spaced custom trays; VC: visible light cure close fit custom trays; VS: visible light cure spaced custom trays

Table (2): The One Way Analysis of Variance (ANOVA) of the Close Fit and Spaced Cold Cure and Visible Light Cure Custom Trays in Relation to the Control Group.

\begin{tabular}{cccccc} 
& Sum of squares & Df & Mean squares & F-value & Sig. \\
\cline { 2 - 6 } $\begin{array}{c}\text { Between } \\
\text { Groups }\end{array}$ & 2.608 & 6 & 0.435 & 78.231 & 0.0 \\
$\begin{array}{c}\text { Within } \\
\text { Groups }\end{array}$ & 0.350 & 63 & 0.006 & & \\
Total & 2.958 & 69 & & & \\
\hline
\end{tabular}

.df: Degree of freedom, Sig. : Significance

Table (3): Duncan Analysis Multiple Range Test of The Close Fit and Spaced Cold Cure and Visible Light Cure Custom Trays in Relation to Heat Cure Custom Trays (Control Group).

\begin{tabular}{cccccccc}
\hline Group & Duncan's grouping* & \multicolumn{5}{c}{ Subset for alpha= 0.05 } \\
& & 1 & 2 & 3 & 4 & 5 & 6 \\
\hline VS & A & 1.03 & & & & & \\
VC & B & & 1.1 & & & & \\
HS & C & & & 1.21 & & & \\
HC & D & & & & 1.3 & & \\
CS & E & & & & & 1.4 & \\
CC & F & & & & & 1.5 \\
\hline
\end{tabular}

*Means with different litters are significantly different atp $\leq 0.05$ 
The results showed that there was significant difference in the removal force (tensile force) between close fit and sp-aced design of the custom tray materials used in this study.

The force necessary to remove the impression by application of a single point tensile force in the anterior of the tray was recorded. The visible light cure custom tray showed less removal value than the heat and. This is related to complete polymerization of the visible light cure resin without residual monomer, and superior mechanical and physical properties of the visible light cure resin when compared with the heat and cold cure acrylic re$\sin ^{(10)}$

The heat cure custom tray showed less removal force value than the cold cure custom tray. This is related to the lower strength of the cold cure acrylic resin than the heat cure acrylic resin which is related to the high plasticizer in the powder, high amount of residual monomer and high porosity. Also the average polymer chain length appears to be less in cold cure acrylic resin, this increase residual monomer content and reduced attack by the monomer on the polymer grains. Furthermore, this unreacted monomer may act as a plasticize that decrease the strength. ${ }^{(1-15)}$

The spaced custom trays for the three materials used in this study showed less value of removal force than the close fit custom trays.This is related to the design of the tray that lead to less pressure during taking the impression that lead to less value of removal force.

\section{CONCLUSIONS}

The results appeared from this study that the visible light cure spaced custom tray lead to less value in removal force and it is recommended to be use when compared with the other types of the trays used in this study.

\section{REFERENCES}

1. Collard EW,Caputo AA,Standlee JP,Trabert KC. Dynamic stresses encountered in impression removal. $J$ Prosthet Dent. 1973;489- 506.

2. Pagniano RD, Scherd RC, Clowson RL, Dageforde RO, Zardiackes LD. Linear dimensional changes of acrylic custom trays. J Prosthet Dent. 1982; 47: 279 283.

3. Fehling AW, Hesby AR, Pelleu GB. Dimensional stability of autopolymerizing acrylic resin impression trays. J Prosthet Dent. 1986; 55: 592 - 597.

4. Mendez AJ. The influence of impression tray on the accuracy of stone casts poured from irreversible hydrocolloid impressions. J Prosthet Dent. 1985; 54:383-391.

5. Gordon GE, Johnson GH, Drennon DG . The effect of tray selection on the accuracy of elastomeric impression materials. $J$ Prosthet Dent. 1990; 63: 12-5.

6. Jown B. Dental laboratory technology. Dentistry cn. 1968; 30: 15 - 18.

7. Ogle RE, Sorensen SE, Lewis EA . A new visible light - cured resin system applied to removable prosthodontics. J Prosthet Dent. 1986; 56: 497 - 506.

8. Khan Z, Razavi R ,Fraunhofer JA. The physical properties of a visible light cured temporary fixed partial denture material. J Prosthet Dent.1988; 60:543 - 545.

9. Philip SB, Kevin BF. Water immersion procedure for making light - cured custom trays with wax spacer. $J$ Prosthet Dent. 1999; 82:741 - 751 .

10. 10. Breeding LC, Dixon DL, Moseley JP .Custom impression trays: Part $1-\mathrm{Me}-$ chanical Properties. J Prosthet Dent. 1994; 71: $31-34$.

11. Anusavice KJ .Philip's science of dental material. $10^{\text {th }}$ ed. Philadelphia, WB Sounder's Co. 1996;PP: 211 - 236, 237 271.

12. Ray NA . Dental materials science. 1998; PP: $1-17,38-48$.

13. Polyzois GL, Tarantili PA, Frangon MJ, Anderpoulos G .Fracture force, deflection at fracture, and toughness of repair denture resin subjected to microwave polymerization or reinforced with wire or glass fiber. J Prosthet Dent. 2001 ; 86: 613 - 619.

14. Craig RG, Powers JM .Restorative dental materials. $11^{\text {th }}$ ed. The CV Mosby Co., St Louis, 2002 ; PP: 186 - 198, 636 - 689.

15. 15. Phoenix RD, Mansueto MA, Ackerman NA, Jones RE .Evaluation of mechanical and thermal properties of commonly used denture base resins. J Prothedont . 2004 ; 13: 17 - 22. 